\title{
Expression of the proteoglycan syndecan-4 and the mechanism by which it mediates stress fiber formation in folliculostellate cells in the rat anterior pituitary gland
}

\author{
Kotaro Horiguchi, Tom Kouki, Ken Fujiwara, Takehiro Tsukada, Floren Ly, \\ Motoshi Kikuchi and Takashi Yashiro \\ Division of Histology and Cell Biology, Department of Anatomy, Jichi Medical University School of Medicine, 3311-1 Yakushiji, Shimotsuke, \\ Tochigi 329-0498, Japan \\ (Correspondence should be addressed to T Yashiro; Email: tyashiro@jichi.ac.jp; K Horiguchi; Email: kota@jichi.ac.jp)
}

\begin{abstract}
Folliculostellate (FS) cells in the anterior pituitary gland appear to have multifunctional properties. FS cells connect to each other at gap junctions and thereby form a histological and functional network. We have performed a series of studies on network formation in FS cells and recently reported that FS cells markedly prolong their cytoplasmic processes and form numerous interconnections with neighboring FS cells in the presence of laminin, an extracellular matrix (ECM) component of the basement membrane. In this study, we investigated the mechanism of this extension of FS cell cytoplasmic processes under the influence of laminin and found that laminin promoted stress fiber formation within FS cells. Next, we noted that formation of stress fibers in FS cells

was mediated by syndecan-4, a transmembrane proteoglycan that binds ECM and soluble factors via their extracellular glycosaminoglycan chain. We then observed that expressions of syndecan-4 and $\alpha$-actinin (a microfilament bundling protein that cross-links actin stress fibers in FS cells) were upregulated by laminin. Using specific siRNA of syndecan-4, actin polymerization of FS cells was inhibited. Our findings suggest that FS cells received a signal from laminin-syndecan4 interaction, which resulted in morphological changes, and that the formation of a morphological and functional network in FS cells was transduced by a syndecan-4-dependent mechanism in the presence of ECM.

Journal of Endocrinology (2012) 214, 199-206
\end{abstract}

\section{Introduction}

The anterior pituitary gland comprises five types of hormone-producing cells plus folliculostellate (FS) cells, which do not produce classical anterior pituitary hormones. Histologically, these six types of anterior pituitary cells aggregate and form clusters surrounded by different types of extracellular matrix (ECM), which provide the necessary mechanical integrity, rigidity, and elasticity for these cells to perform their respective roles (Soji \& Herbert 1989, Kaidzu et al. 2000, Paez-Pereda et al. 2005). It has been shown that lobular structures surrounded by ECM are responsible for organizing aggregations of anterior pituitary cells into a functional unit in the anterior pituitary gland (Soji \& Herbert 1989, Shirasawa et al. 2004). FS cells are located in the core of these lobular structures.

Accumulating evidence indicates that FS cells have numerous possible functions. They have been reported to act as stem cells, phagocytes, and cells that regulate hormone release (Inoue et al. 1999, Allaerts \& Vankelecom 2005). Regarding the histological features of FS cells in the anterior pituitary gland, FS cells are interconnected via their

cytoplasmic processes and formed gap junctions at their adhesion sites (Morand et al. 1996, Sato et al. 2005). The network formed by these connections is referred to morphologically as the FS cell network (Sato et al. 2005). In addition, by means of $\mathrm{Ca}^{2+}$ waves through the gap junction channels, FS cells stimulate the building of a largescale communication network with the neighboring FS cells in the anterior pituitary gland (Fauquier et al. 2001, Sato et al. 2005). These findings have led to speculation regarding the function of FS cells. One hypothesis is that FS cells transmit signals via gap junctions so as to regulate hormone release from hormone-producing cells, in addition to the established hypophyseal-portal system (Shirasawa et al. 2004, Sato et al. 2005).

We conducted a series of studies that used living-cell imaging in primary culture of anterior pituitary cells to investigate FS cell network formation and found that FS cells extend and contract their cytoplasmic processes by rearranging their actin cytoskeleton, thereby establishing interconnections between FS cells (Horiguchi et al. 2010). Furthermore, we showed that FS cells in the presence of ECM markedly prolong their cytoplasmic processes, form numerous 
interconnections with neighboring FS cells, and promote assembly of the FS cell network (Horiguchi et al. 2010, 2011a). However, it is not clear how FS cells under the influence of ECM prolong their cytoplasmic processes and initiate network construction with other FS cells in primary culture. By means of signal transduction, ECM arranges the actin cytoskeleton via families of transmembrane receptors called integrins (Hynes 2002) and syndecans (Parsons et al. 2000, Dovas et al. 2006, Xian et al. 2010). In this study, we therefore attempted to identify the mechanism responsible for the extension of FS cell cytoplasmic processes. First, we observed stress fiber formation in FS cells in the presence of laminin, an ECM component of the basement membrane. Stress fibers are composed of bundles of 10-30 actin filaments, and these bundles are held together with the actincrosslinking protein $\boldsymbol{\alpha}$-actinin (Pellegrin \& Mellor 2007). On the basis of their subcellular location, observed stress fibers are grouped into three classes, i.e. ventral stress fibers, dorsal stress fibers, and transverse arcs (Small et al. 1998). Ventral stress fibers are the most common and are located along the base of the cytoplasm (Pellegrin \& Mellor 2007). Finally, we analyzed the downstream events of ECM signaling with mediation by syndecan-4, which is a single-pass transmembrane proteoglycan that binds a number of signaling molecules potentially linked with stress fiber formation.

\section{Materials and Methods}

\section{Animals}

Transgenic S100b-GFP rats that express green fluorescent protein (GFP) under the control of the promoter of S100 $\beta$ protein gene - a marker of FS cells - were donated by Prof. K Inoue of Saitama University and bred in our laboratory (Itakura et al. 2007). Eight- to ten-week-old male rats weighing 250-300 g were given ad libitum access to food and water and housed under conditions of a $12 \mathrm{~h}$ light: $12 \mathrm{~h}$ darkness cycle. Rats were killed by exsanguination from the right atrium under deep pentobarbital anesthesia and then perfused with $\mathrm{Ca}^{2+}$ - and $\mathrm{Mg}^{2+}$-free Hanks' solution for primary culture. All animal experiments were performed after receiving approval from the Institutional Animal Experiment Committee of Jichi Medical University and were conducted in accordance with the Institutional Regulation of Animal Experiments and Fundamental Guideline for Proper Conduct of Animal Experiment and Related Activities in Academic Research Institutions, under the jurisdiction of the Japanese Ministry of Education, Culture, Sports, Science, and Technology.

\section{Cell culture}

Anterior pituitary cells of male S100b-GFP rats were dispersed as described previously (Horiguchi et al. 2008). Dispersed cells were then plated onto eight-well glass chamber slides $\left(1 \mathrm{~cm}^{2} /\right.$ well; Nalge Nunc Int., Rochester, NY, USA) with or without a coating of laminin $\left(10 \mu \mathrm{g} / \mathrm{cm}^{2}\right.$; Millipore, Bedford, MA, USA) at a density of $1 \times 10^{5}$ cells $/ \mathrm{cm}^{2}$ in $400 \mu \mathrm{l}$ of Medium 199 with Earle's salts (Invitrogen) supplemented with 10\% fetal bovine serum (Sigma-Aldrich Corp.), $0.5 \mathrm{U} / \mathrm{ml}$ of penicillin, and $0.5 \mu \mathrm{g} / \mathrm{ml}$ of streptomycin (Invitrogen). Other dispersed cells were separated into GFP-positive and GFP-negative cells by a cell sorter (MoFlo XDP: Beckman Coulter, Inc., Fullerton, CA, USA). GFP-positive cells were plated onto eight-well glass chamber slides (Nalge Nunc Int.), with or without a coating of $10 \mu \mathrm{g} / \mathrm{cm}^{2}$ of laminin at a density of $1 \times 10^{5}$ cells $/ \mathrm{cm}^{2}$. Cells were then cultured for $72 \mathrm{~h}$ at $37^{\circ} \mathrm{C}$ in a humidified atmosphere of $5 \% \mathrm{CO}_{2}$ and $95 \%$ air.

\section{Fluorescent cytochemistry of actin filaments}

To observe cellular localization of actin filaments, cells were fixed with $4 \%$ paraformaldehyde in $25 \mathrm{mM}$ phosphate buffer (PB, $\mathrm{pH} \mathrm{7.4)} \mathrm{for} 20 \mathrm{~min}$ and permeabilized with $0 \cdot 5 \%$ Triton $\mathrm{X}-100$ in PBS for $5 \mathrm{~min}$ at room temperature. Fixed cells were incubated with $0 \cdot 1 \mu \mathrm{M}$ rhodamine-phalloidin (Cytoskeleton, Inc., Denver, CO, USA) for $30 \mathrm{~min}$ at room temperature and washed with PBS. Cells were scanned at a thickness of $1 \mu \mathrm{m}$ using a confocal laser microscope (FV1000; Olympus Corp., Tokyo, Japan).

\section{Electron microscopic observation}

For observation of stress fiber, FS cells in primary culture on laminin-coated surfaces were fixed with $2 \cdot 5 \%$ glutaraldehyde in $0 \cdot 1 \mathrm{M} \mathrm{PB}, \mathrm{pH} 7 \cdot 4$, for $1 \mathrm{~h}$ at $4{ }^{\circ} \mathrm{C}$. Then, FS cells were postfixed with $1 \% \mathrm{OsO}_{4}$ in $0 \cdot 1 \mathrm{M} \mathrm{PB}$ for $1 \mathrm{~h}$ at $4{ }^{\circ} \mathrm{C}$, dehydrated in a series of graded alcohols, and embedded in epoxy resin (Quetol 812; Nissin EM Co., Tokyo, Japan). FS cells were sectioned into ultrathin slices using a ReichertNissei Ultracut S (Leica Microsystems, Wetzlar, Germany), stained with uranyl acetate and lead citrate, and then observed under a Hitachi H-7600 electron microscope (Hitachi).

\section{Immunoblot analysis}

After primary culture, cells on six wells were washed in PBS and lysed in RIPA buffer $(20 \mathrm{mM}$ Tris, $150 \mathrm{mM} \mathrm{NaCl}$, $2 \mathrm{mM}$ EDTA, 0.1\% v/v SDS, $1 \% \mathrm{v} / \mathrm{v}$ Triton X-100, $\mathrm{pH} 7 \cdot 5)$, and total protein was estimated by using a bicinchoninic acid protein assay kit (Pierce, Rockford, IL, USA) according to the manufacturer's instructions. Twenty micrograms of protein from each sample were applied to $12 \%$ SDS-PAGE. Proteins were then transferred electrophoretically to Immobilon-P transfer membrane (Millipore). The membrane was blocked with $5 \%(\mathrm{w} / \mathrm{v})$ nonfat dried milk in TBST $(50 \mathrm{mM}$ Tris, $100 \mathrm{mM} \mathrm{NaCl}, 0 \cdot 1 \% \mathrm{v} / \mathrm{v}$ Tween 20, pH 7·4) for $1 \mathrm{~h}$. After washing with TBST, the membrane was incubated overnight with mouse monoclonal $\boldsymbol{\alpha}$-actinin (1:5000; Enzo Life Sciences, Inc., Farmingdale, NY, USA) or rabbit polyclonal syndecan-4 (1:10 000; Assay Biotechnology Company, Inc., Sunnyvale, CA, USA) antibodies, diluted in Can Get Signal 
Solution (Toyobo, Osaka, Japan), followed by TBST washes, and incubated for $1 \mathrm{~h}$ with HRP-labeled secondary antibodies (Envision + System-HRP, anti-rabbit, Dako, Glostrup, Denmark). After washing with TBST, specific immunoreactivity was visualized using a Chemiluminescence ECL Plus System (GE Healthcare, Mississauga, ON, Canada) with lumi-shot film (Fujifilm, Tokyo, Japan). The film was scanned, and densitometric analysis was performed with ImageJ Software (National Institutes of Health, Bethesda, MD, USA). The results were normalized with $\beta$-actin. Each analysis was performed in triplicate.

\section{Quantification of $m R N A$ levels by real-time RT PCR}

Total RNA fractions were prepared, and cDNA was synthesized as described previously (Horiguchi et al. 2011a). Quantitative real-time PCR (ABI PRISM 7900HT; Applied Biosystems) was performed by using gene-specific primers and SYBR Premix Ex Taq (Takara, Tokyo, Japan) containing SYBR Green I. The following primers were used to amplify cDNA fragments of syndecan-4 (GenBank accession no. NM_012649): forward 5'-GCCTTGAGCAGGACTCTGAC- $3^{\prime}$ and reverse $5^{\prime}$-TTCTCGGGGATGTGGTTATC-3' (124 bp); $\alpha$-actinin (BC074001): forward $5^{\prime}$-CAACATGGGAGAGGCAGAAT- $3^{\prime}$ and reverse $5^{\prime}$-TCCGCTGTATCTGTGTCAGC-3' (126 bp); PKCa (NM_001105713): forward $5^{\prime}$-ATGGCACACATGGAGCTGTA-3' $3^{\prime}$ and reverse 5'-ATGCAAAATCCATTGCATGA-3' (118 bp); FAK (ENSRNOT00000011219): forward 5'-CCTGTGGATCCTGAAGCATT- $3^{\prime}$ and reverse $5^{\prime}$-TCTTGATGCAGTTGGGAGTG-3' (116 bp). For normalization, we also quantified glyceraldehyde 3-phosphate dehydrogenase (GAPDH, M_17701): forward 5'-AAGGGCTCATGACCACAGTC-3' and reverse 5'-GGATGCAGGGATGATGTTCT-3' (116 bp). Relative quantification was conducted using the standard curve method and was performed in triplicate.

\section{siRNA for syndecan-4}

For siRNA transfection, the culture medium was replaced by $400 \mu \mathrm{l}$ Medium 199 with Earle's salts (Invitrogen) supplemented with 10\% fetal bovine serum (Sigma-Aldrich Corp.), $0.5 \mathrm{U} / \mathrm{ml}$ penicillin, and $0.5 \mu \mathrm{g} / \mathrm{ml}$ streptomycin (Invitrogen), siRNA against syndecan-4 mRNA $(0 \cdot 2 \mu \mathrm{M}, \mathrm{Rn}$ _Sdc4_7; Qiagen), and INTERFER in $(1: 100 \mathrm{v} / \mathrm{v})$ transfection reagent at $24 \mathrm{~h}$. Nonsilencing siRNA with no homology to any known mammalian gene was used as a negative control (Qiagen). After that, the GFPpositive cells were cultured for $48 \mathrm{~h}$, and $2 \times 10^{5}$ and $6 \times 10^{5}$ cells were used for real-time RT-PCR and immunoblot analysis respectively. For observation of actin filaments, we retrieved the GFP-positive cells at $48 \mathrm{~h}$ using $\mathrm{Ca}^{2+}$ - and $\mathrm{Mg}^{2+}$-free Hanks' solution containing 0.3\% ethylenediaminetetraacetic acid (Wako Pure Chemicals, Osaka, Japan) for $20 \mathrm{~min}$ at $37^{\circ} \mathrm{C}$, and redispersed GFP-positive cells were cultured on laminin-coated surface for $24 \mathrm{~h}$. After that, the GFP-positive cells were fixed for the abovementioned rhodamine-phalloidin staining. Each analysis was performed in triplicate.

\section{Immunocytochemistry}

Cultured cells fixed with $4 \%$ paraformaldehyde in $50 \mathrm{mM}$ $\mathrm{PB}$ for $20 \mathrm{~min}$ at room temperature were first immersed in PBS containing $2 \%$ normal goat serum for $20 \mathrm{~min}$ at $30^{\circ} \mathrm{C}$, then incubated with $\boldsymbol{\alpha}$-actinin (1:200; Enzo Life Sciences, Inc.) or rabbit polyclonal syndecan-4 (1:400; Assay Biotechnology Company, Inc.) antibodies for overnight at room
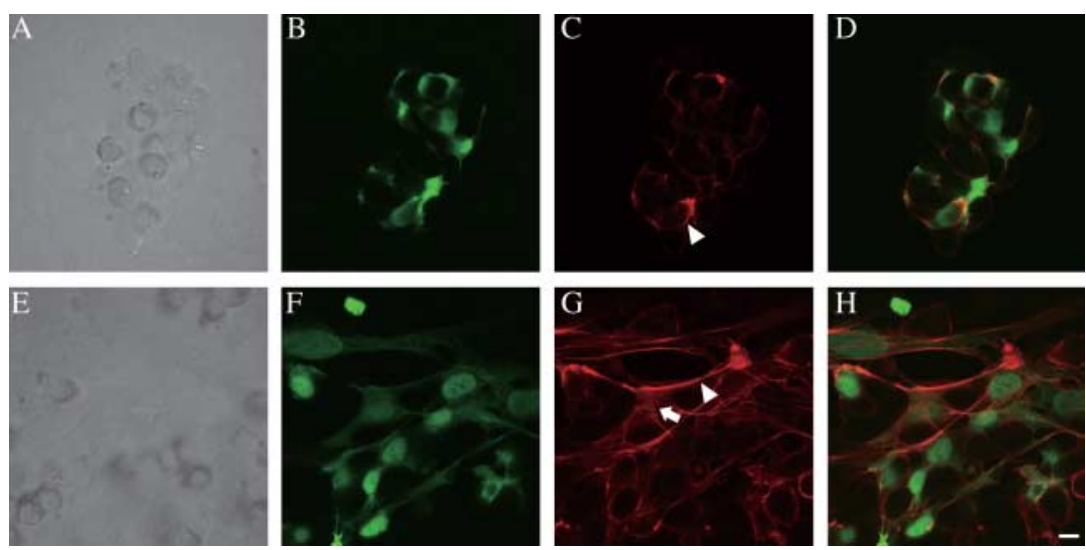

Figure 1 Stress fibers in primary culture of anterior pituitary cells on uncoated and laminin-coated surfaces. (A, B, C and D) Primary culture on uncoated surface at $72 \mathrm{~h}$. $(\mathrm{E}, \mathrm{F}, \mathrm{G}$ and $\mathrm{H}$ ) Primary culture on laminin-coated surface at $72 \mathrm{~h}$. (A and $\mathrm{E}$ ) Phase-contrast images. (B and F) GFP images (green, FS cells). (C and G) Rhodamine-phalloidin staining (red, stress fiber). ( $D$ and $H$ ) Superimposition of $B$ and $C$ and $F$ and $G$ respectively. Ventral or dorsal stress fibers (arrow) formed in the cytoplasm of FS cells, and transverse arcs formed beneath the cell membrane (arrowhead). Scale bar, $10 \mu \mathrm{m}$. 

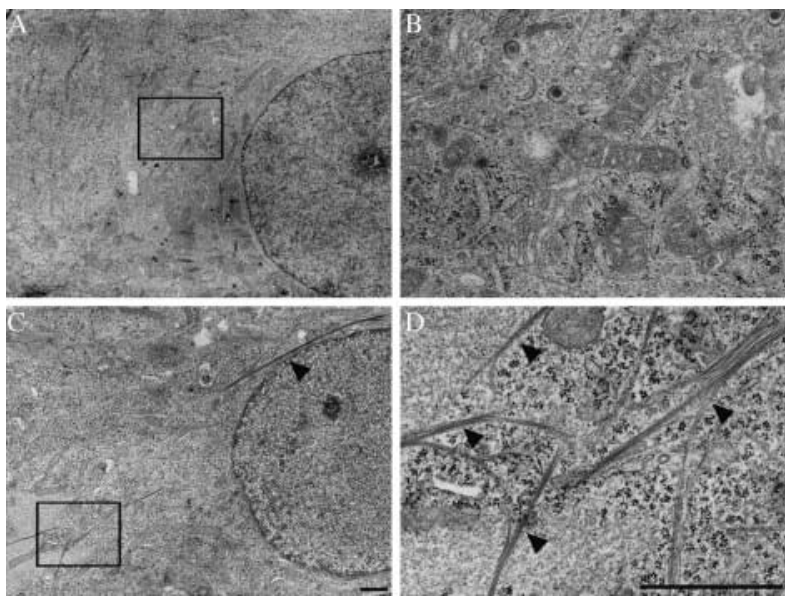

Figure 2 Electron micrographs of FS cells cultured on uncoated and laminin-coated surfaces for $72 \mathrm{~h}$. (A) Lower magnification on uncoated surface. (B) Higher magnification of area indicated by the box in A. (C) Lower magnification on laminin-coated surface. (D) Higher magnification of area indicated by the box in C. Bundles of parallel microfilaments were present (arrowheads). Scale bars, $500 \mathrm{~nm}$.

temperature. After washing with PBS, cells were incubated in PBS with Alexa Fluor 568-conjugated goat anti-mouse IgG (Invitrogen) diluted to 1:200. Absence of an observable nonspecific reaction was confirmed using normal mouse or rabbit serum. Cells were scanned at a thickness of $1 \mu \mathrm{m}$ using a confocal laser microscope (FV1000; Olympus Corp.).

\section{Statistical analysis}

Results are presented as mean \pm s.E.M. The $t$-test was used to compare differences between two groups. A $P$ value $<0 \cdot 05$ was considered to indicate statistical significance.

\section{Results}

Laminin-induced stress fiber formation in FS cells

We used rhodamine-phalloidin staining to observe the filamentous actin arrangement of anterior pituitary cells in primary culture. On the uncoated surface, actin filaments were detected along the elongated cytoplasmic processes of FS cells (Fig. 1A, B, C and D, arrowhead). However, actin filaments were far more numerous in the cytoplasm and cytoplasmic processes of FS cells on the laminin-coated surface (Fig. 1E, F, G and H, arrow and arrowhead), which suggest that stress fibers formed in the cytoplasm of FS cells on the laminin-coated surface. GFP-negative cells, which are primarily hormone-producing cells, retained their round shape and did not form stress fibers on either the uncoated or laminin-coated surfaces (Fig. 1).

\section{Electron microscopic observation of FS cells}

To verify the presence of actin stress fibers in FS cells, we used an electron microscope to observe FS cells in primary culture on uncoated (Fig. 2A and B) and laminin-coated surfaces (Fig. 2C and D). There were few actin filaments in the cytoplasm of FS cells on the uncoated surface (Fig. 2B). By contrast, we noted bundles of parallel microfilaments in FS cells on the laminin-coated surface (Fig. 2C and D).

\section{Expression of syndecan-4 in FS cells}

A cell sorter was used to isolate FS cells from male S100bGFP rat anterior pituitary for real-time RT-PCR and western blotting. To determine whether FS cells express syndecan-4, we performed quantitative real-time RT-PCR. Syndecan-4 expression was significantly higher in GFP-positive cells than in GFP-negative cells (Fig. 3A). In western blot analysis, syndecan-4 immunoreactivity was also detected in FS cells as an $\sim 22 \mathrm{kDa}$ band, which conforms to the expected size of rat syndecan-4 core protein (Fig. 3B).

Change in syndecan- $4 \mathrm{mRNA}$ and protein expression in FS cells on laminin

To determine whether laminin affects syndecan-4 and $\alpha$-actinin gene expression in FS cells, we performed quantitative real-time RT-PCR. $\alpha$-Actinin is a $100 \mathrm{kDa}$ microfilament bundling protein that cross-links actin stress fibers in muscle and nonmuscle cells (Lazarides \& Burridge 1975, Otey \& Carpen 2004). As compared with the uncoated surface, gene expressions of syndecan- 4 and $\alpha$-actinin were higher in cells on the laminin-coated surface at $72 \mathrm{~h}$ (Fig. 4A and $\mathrm{B})$. However, the expressions of protein kinase $\mathrm{C} \alpha$ $(\mathrm{PKC} \alpha)$ and focal adhesion kinase (FAK), which are signaling molecules of syndecan- 4 and integrin $\beta 1$ in stress fiber assembly, were not higher in cells on the laminin-coated surface (Fig. 4C and D). We also examined localization of

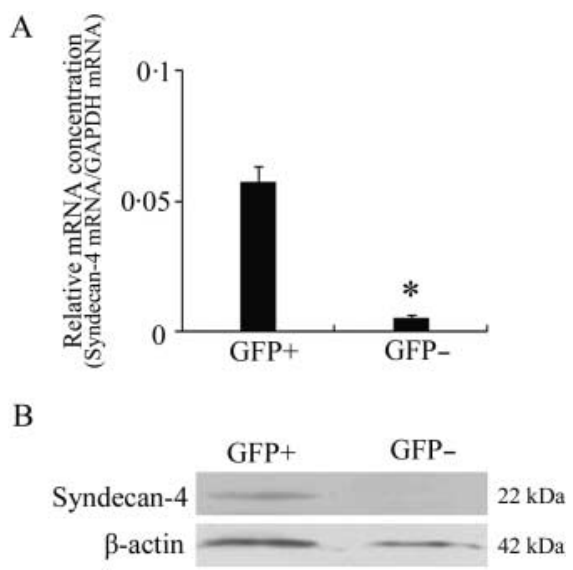

Figure 3 Syndecan-4 expression in FS cells. (A) Expression of syndecan-4 mRNA in GFP-positive (GFP+, FS cells) and GFPnegative $(\mathrm{GFP}-)$ cells, as determined by real-time RT-PCR, was normalized with an internal control (GAPDH; mean \pm s.E.M., $n=3)$. $* P<0 \cdot 01$. (B) Syndecan-4 protein was analyzed by western blotting. The upper panel shows syndecan-4 and the lower panel shows $\beta$-actin (loading control). 
A

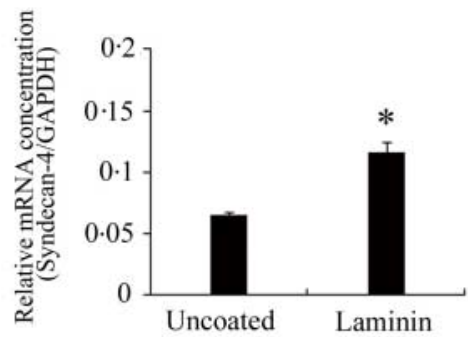

$\mathrm{C}$

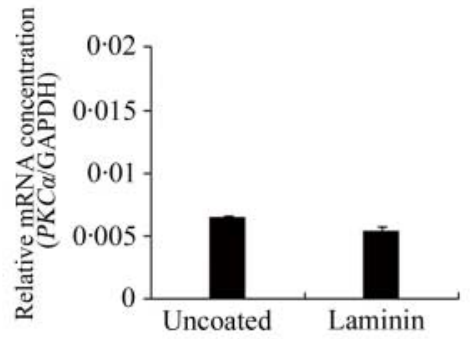

B

D
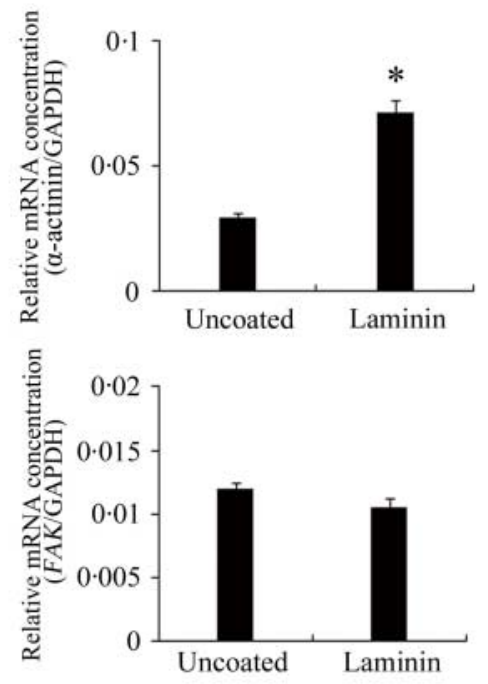
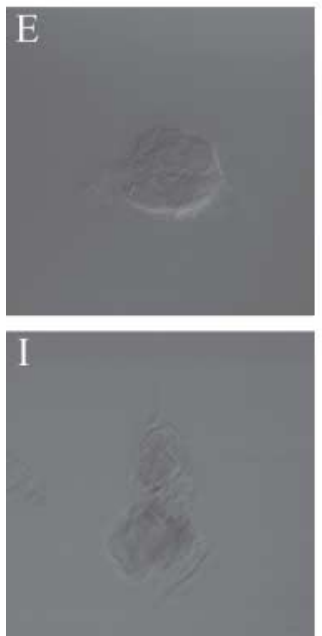
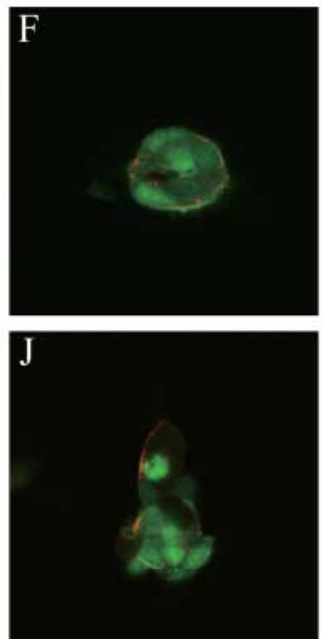
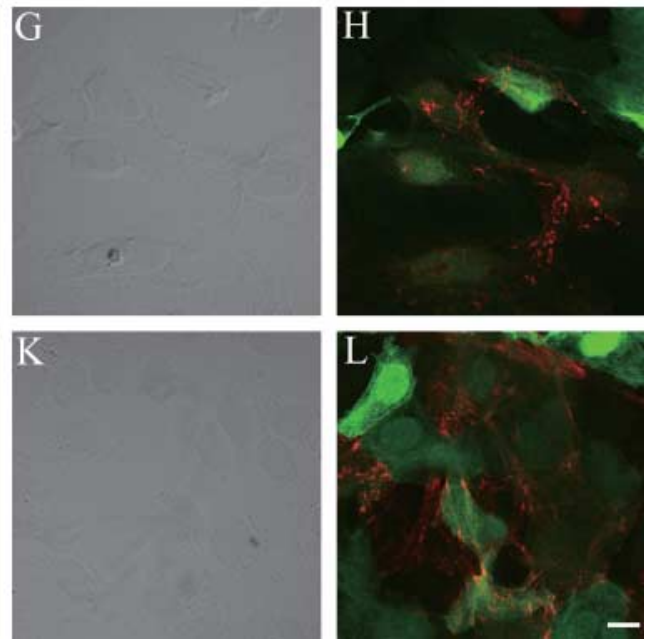

Figure 4 Syndecan-4 expression in primary culture of FS cells after 72-h incubation. (A, B, C and D) Expressions of syndecan-4, $\alpha$-actinin, $P K C \alpha$, and FAK mRNA, respectively, as determined by real-time RT-PCR, were normalized with an internal control (GAPDH; mean \pm s.E.M., $n=4)$. Syndecan-4 and $\alpha$-actinin mRNA expression was significantly higher on the laminin-coated surface (laminin) than on the uncoated surface (uncoated). ${ }^{*} P<0 \cdot 01$. (E, F, G and H, and I, J, K and L) Immunocytochemistry of syndecan-4 and $\alpha$-actinin in primary culture of FS cells respectively. (E, F, I and J) 72-h culture of FS cells on uncoated surface. (G, H, K and L) 72-h culture of FS cells on laminin-coated surface. $(E, G, I$ and $K)$ Phase-contrast images. (F, H, J and L) Fluorescent images. Syndecan- 4 and $\alpha$-actinin (red) immunoreactivity was observed in FS cells (green). Scale bar, $10 \mu \mathrm{m}$.

syndecan- 4 and $\alpha$-actinin by immunocytochemistry at $72 \mathrm{~h}$ in primary culture on uncoated and laminin-coated surfaces. Immunoreactive syndecan- 4 and $\alpha$-actinin were located on cytoplasmic processes of FS cells on both the uncoated and laminin-coated surfaces (Fig. 4E, F, G, H, I, J, K, and L). Syndecan-4 and $\boldsymbol{\alpha}$-actinin immunoreactivity in FS cells was clearly greater on the laminin-coated surface (Fig. 4H and L) than on the uncoated surface (Fig. 4F and J).

\section{Knockdown of syndecan-4 by siRNA}

To examine the functional role of syndecan-4 in stress fiber formation in FS cells, we used siRNA to downregulate syndecan-4 expression in FS cells on the laminin-coated surface. When syndecan-4 was downregulated with a specific siRNA, its expression decreased (Fig. 5A, C and D). In addition, quantitative analysis revealed that $\boldsymbol{\alpha}$-actinin expression in syndecan-4 siRNA-treated FS cells was lower than in control FS cells (Fig. 5B, C and E). Finally, rhodamine-phalloidin staining was used to examine the effect of syndecan-4 silencing on stress fiber formation in FS cells and, in contrast with control (Fig. 5F, G, H and I), ventral and dorsal stress fibers were not observed in FS cells after syndecan4 downregulation (Fig. 5J, K, L and M). However, we did observe actin filaments beneath cell membranes (transverse arcs) of FS cells after syndecan-4 silencing (Fig. 5J, K, L and M). 
A

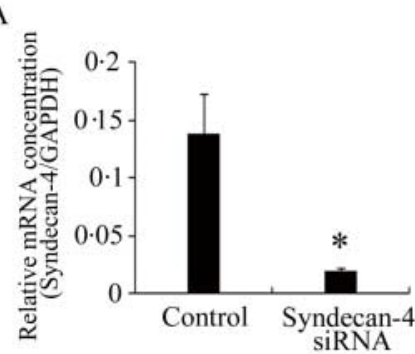

$\mathrm{C}$

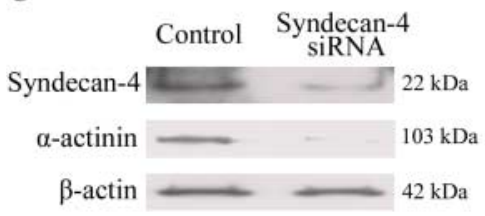

B

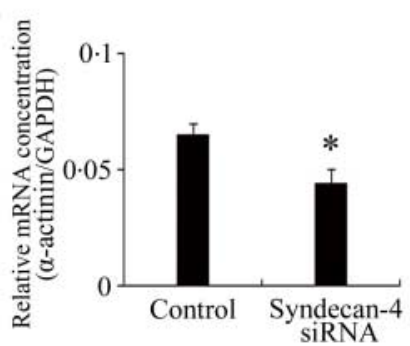

D

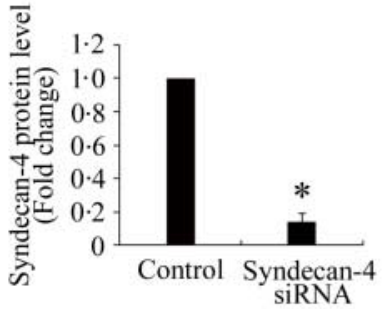

E

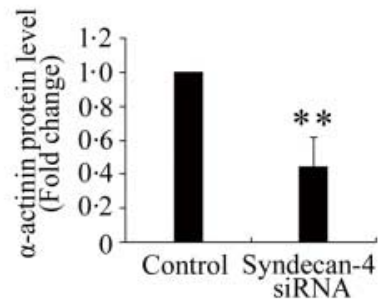

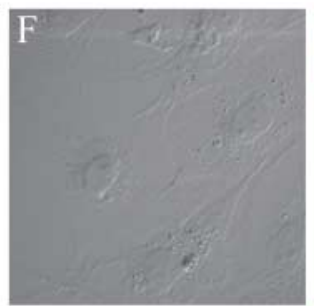
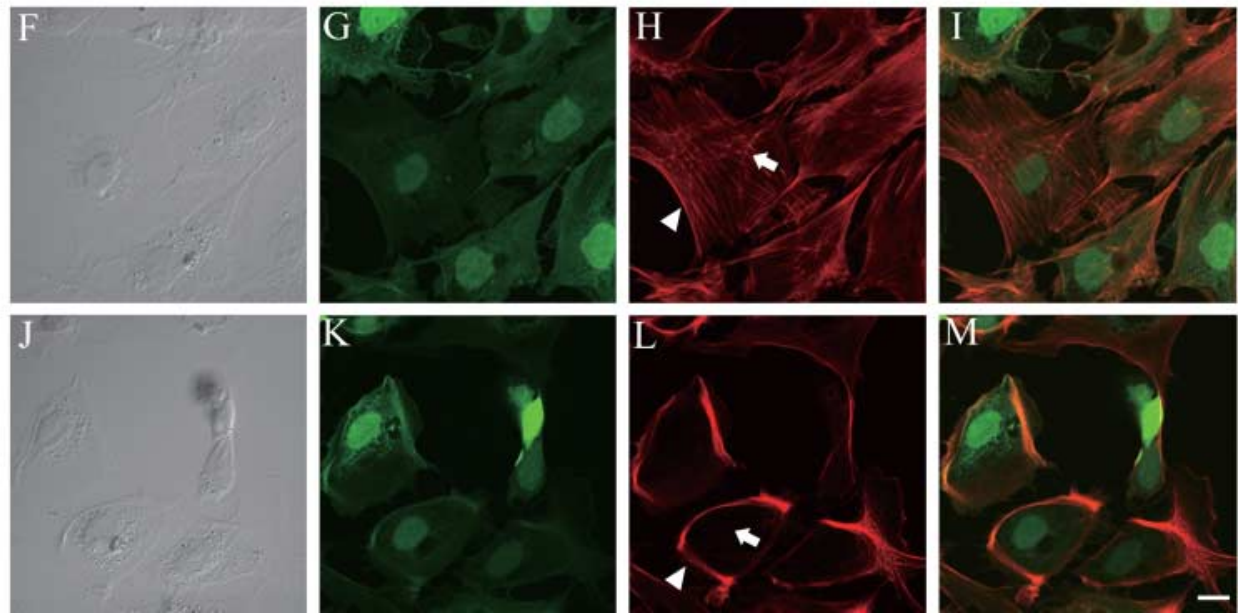

Figure 5 Downregulation of syndecan-4 by siRNA. (A and B) Expressions of syndecan- 4 and $\alpha$-actinin mRNA, respectively, as determined by real-time RT-PCR, were normalized with an internal control (GAPDH) for 48-h incubation after FS cells were transfected with siRNA (mean \pm S.E.M., $n=4)$. Syndecan- 4 and $\alpha$-actinin mRNA expression was significantly lower in the experimental group than in the control. (C) The protein levels of syndecan- 4 and $\alpha$-actinin were determined by western blotting. The top panel shows syndecan-4, the middle panel shows $\alpha$-actinin, and the bottom panel shows $\beta$-actin as the loading control. (D and E) Western blotting data from three experiments (mean \pm S.E.M., $n=3$ ) were quantified by densitometry and normalized with $\beta$-actin. Levels of syndecan- 4 and $\alpha$-actinin protein (syndecan-4 siRNA) were calculated as ratios of control values (Control). After siRNA treatment, the protein level of syndecan- 4 (D) and $\alpha$-actinin (E) in FS cells (syndecan-4 siRNA) was significantly lower than in control (Control). ${ }^{*} P<0 \cdot 01 ; * * P 0 \cdot 05$. (F, G, H and I) Rhodamine-phalloidin staining for 48-h incubation after FS cells were transfected by siRNA ( F, G, H and I, control siRNA and J, H, I, J, K, L and M, syndecan-4 siRNA). ( $F$ and J) Phase-contrast images. ( $\mathrm{G}$ and K) GFP images (green, FS cells). ( $\mathrm{H}$ and $\mathrm{L}$ ) Rhodamine-phalloidin staining (red, stress fiber). (I and M) Superimposition of $G$ and $H$, and $K$ and $L$ respectively. Ventral and dorsal stress fiber formation (arrow) in the cytoplasm of FS cells was inhibited by siRNA specific for syndecan-4, but formation of transverse arcs beneath the cell membrane of FS cells (arrowhead) was not inhibited. Scale bar, $10 \mu \mathrm{m}$.

\section{Discussion}

In this study, we observed that morphological changes in FS cells in the presence of laminin were strongly dependent on increased stress fiber formation. We also found that stress fiber formation was transduced by a syndecan-4-mediated mechanism in FS cells.
In a recent study, we showed that laminin markedly increased the extension of cytoplasmic processes and their interconnections in FS cells (Horiguchi et al. 2010). In this study, we found that actin filaments were more numerous in FS cells in the presence of laminin (Fig. 1). Furthermore, we isolated pure FS cells from the anterior pituitary of S100bGFP rat, so as to eliminate the physical and functional effects 
of hormone-producing cells. This allowed us to examine the direct involvement of laminin on actin polymerization of FS cells. As shown in Figs 2 and 4, it is clear that laminin directly affected the extension of cytoplasmic processes by means of stress fiber formation in FS cells.

ECM transduces signals to cells through the integrin family of cell-surface receptors (Hynes 2002). Cell-ECM adhesion through integrin is the starting point for stress fiber formation in cells (Defilippi et al. 1999, Wiesner et al. 2005). Integrins comprise the $\alpha$ - and a $\beta$-subunits, which can form heterodimers. In mammals, $18 \alpha$-integrin and eight $\beta$-integrin subunits have been described, and these can associate in a heterodimeric fashion to form at least 24 different receptors (Hynes 2002). We reported that FS cells bind laminin through integrin- $\alpha 3 \beta 1$ and/or $-\alpha 6 \beta 1$ and that an antibody that inhibits the integrin- $\beta 1$ cascade blocked the extension of cytoplasmic processes in FS cells (Horiguchi et al. 2011a,b). There is little doubt that stress fiber formation in FS cells also depends on FS cell-laminin adhesion through integrin- $\alpha 3 \beta 1$ and/or $-\alpha 6 \beta 1$. However, there are several signal transduction pathways after cells adhere to ECM through integrin- $\beta 1$, including FAK (Parsons et al. 2000) and syndecan-4-mediated $P K C \alpha$ (PRKCA) signaling (Dovas et al. 2006, Pellegrin \& Mellor 2007), which lead to $\alpha$-actinin transcription and contribute to stress fiber formation. Syndecans are a family of transmembrane proteoglycans that bind ECMs and soluble factors (Simons \& Horowitz 2001). A number of studies have shown that syndecan-4, which acts as a cell-surface receptor via its extracellular glycosaminoglycan chains, is involved in actin polymerization (Simons \& Horowitz 2001). Syndecan-4 is expressed in fibroblasts (Sawaguchi et al. 2006), skeletal and smooth muscle cells (Cornelison et al. 2001, Li \& Chaikof 2002), chondrocytes (Barre et al. 2000), and Sertoli cells (Brucato et al. 2000). As shown in Figs 3 and 4, FS cells in the anterior pituitary also expressed syndecan-4, and its expression increased in the presence of laminin. Furthermore, although ventral and dorsal stress fiber formation in FS cells was inhibited by siRNA specific for syndecan-4, transverse arc formation was not inhibited (Fig. 5). These results suggest that actin polymerization or arrangement in FS cells was mediated by syndecan- 4 after cells adhered to ECM through integrin. However, the mechanism responsible for laminin-induced syndecan-4 upregulation in FS cells remains to be elucidated.

It is interesting that the expressions of FAK and PKC $\alpha$ were not upregulated by laminin in FS cells (Fig. 4). Greene et al. (2003) reported that syndecan-4 is able to influence the actin cytoskeleton because $\alpha$-actinin directly binds the cytoplasmic domain. Because of its unusual molecular structure, $\alpha$-actinin contributes to stability and plasticity in a variety of actin-based arrangements. It forms an antiparallel dimer with an actinbinding site at the $\mathrm{N}$-terminus of each monomer (Otey \& Carpen 2004). We therefore speculate that FAK and $P K C \alpha$ signaling do not have roles in stress fiber formation in FS cells. Recently, we reported that hormone-producing cells also expressed integrin- $\beta 1$ and observed little morphological change or extension of cytoplasmic processes of these cells in the presence of laminin (Horiguchi et al. 2010). Thus, the difference in the response to laminin is likely due to syndecan-4 expression (Fig. 3). Our present findings indicate that the syndecan-4-mediated mechanism was specific to FS cells in the anterior pituitary gland.

In the anterior pituitary gland, the lobular structures surrounded by ECM have a role in cell aggregation (Soji \& Herbert 1989, Shirasawa et al. 2004). Knowledge of the topographic features of FS cells is essential in understanding these lobular structures, the location of FS cells in the core of the lobular structure, and the characteristic envelopment of hormone-producing cells by their cytoplasmic processes, the tips of which attach to the ECM (Soji \& Herbert 1989, Inoue et al. 1999, Shirasawa et al. 2004). In our studies on FS cell activity in the presence of ECM (Horiguchi et al. 2010, 2011a,b), we have shown that FS cells markedly extend their cytoplasmic processes and form networks at gap junctions. In this study, we have shown that FS cells under the influence of laminin extend their cytoplasmic processes due to a syndecan-4-dependent mechanism that leads to activation of $\alpha$-actinin in FS cells. These findings suggest that FS cells have important functional roles in determining and/or maintaining local cellular arrangement in the presence of ECM. Future study is needed to investigate the action of hormone-producing cells and their behavior in the presence of ECM.

\section{Declaration of interest}

The authors declare that there is no conflict of interest that could be perceived as prejudicing the impartiality of the research reported.

\section{Funding}

This work was partly supported by a Grant-in-Aid for Scientific Research (C) $(21570067,22590192)$ and a Grant-in-Aid for Young Scientists (B) (22790190) from the Ministry of Education, Culture, Sports, Science and Technology of Japan, as well as by promotional funds for the Keirin Race of the Japan Keirin Association.

\section{Author contribution statement}

$\mathrm{K} \mathrm{H}$ collected data, contributed to the Discussion, wrote the manuscript, and reviewed and edited the manuscript. T K collected data. K F collected data and contributed to the Discussion. $\mathrm{T} \mathrm{T}$ collected data and contributed to the Discussion. L F reviewed and edited the manuscript. M K reviewed and edited the manuscript. T Y contributed to the Discussion, wrote the manuscript, and reviewed and edited the manuscript.

\section{Acknowledgements}

The authors thank Prof. K Inoue (Saitama University, Japan) for supplying the transgenic rats. They are grateful to $M$ Yatabe for her excellent technical assistance and to Prof. Y Hanazono and Y Furukawa for their 
support in fluorescence-activated cell sorting. They also thank David Kipler, ELS of Supernatant Communications for revising the language of the manuscript.

\section{References}

Allaerts W \& Vankelecom H 2005 History and perspectives of pituitary folliculo-stellate cell research. European Journal of Endocrinology 153 1-12. (doi:10.1530/eje.1.01949)

Barre PE, Redini F, Boumediene K, Vielpeau C \& Pujol JP 2000 Semiquantitative reverse transcription-polymerase chain reaction analysis of syndecan-1 and -4 messages in cartilage and cultured chondrocytes from osteoarthritic joints. Osteoarthritis and Cartilage 8 34-43. (doi:10.1053/joca. 1999.0286)

Brucato S, Harduin-Lepers A, Godard F, Bocquet J \& Villers C 2000 Expression of glypican-1, syndecan-1 and syndecan-4 mRNAs protein kinase C-regulated in rat immature Sertoli cells by semi-quantitative RT-PCR analysis. Biochimica et Biophysica Acta 1474 31-40. (doi:10.1016/ S0304-4165(00)00006-4)

Cornelison DD, Filla MS, Stanley HM, Rapraeger AC \& Olwin BB 2001 Syndecan-3 and syndecan- 4 specifically mark skeletal muscle satellite cells and are implicated in satellite cell maintenance and muscle regeneration. Developmental Biology 239 79-94. (doi:10.1006/dbio.2001.0416)

Defilippi P, Olivo C, Venturino M, Dolce L, Silengo L \& Tarone G 1999 Actin cytoskeleton organization in response to integrin-mediated adhesion. Microscopy Research and Technique 47 67-78. (doi:10.1002/(SICI)10970029(19991001) 47:1 <67::AID-JEMT7> 3.0.CO;2-P)

Dovas A, Yoneda A \& Couchman JR 2006 PKCalpha-dependent activation of RhoA by syndecan- 4 during focal adhesion formation. Journal of Cell Science 119 2837-2846. (doi:10.1242/jcs.03020)

Fauquier T, Guérineau NC, McKinney RA, Bauer K \& Mollard P 2001 Folliculostellate cell network: a route for long-distance communication in the anterior pituitary. PNAS 98 8891-8896. (doi:10.1073/pnas.151339598)

Greene DK, Tumova S, Couchman JR \& Woods A 2003 Syndecan-4 associates with alpha-actinin. Journal of Biological Chemistry 278 7617-7623. (doi:10.1074/jbc.M207123200)

Horiguchi K, Fujiwara K, Kouki T, Kikuchi M \& Yashiro T 2008 Immunohistochemistry of connexin 43 throughout anterior pituitary gland in a transgenic rat with green fluorescent protein-expressing folliculostellate cells. Anatomical Science International 83 256-260. (doi:10.1111/ j.1447-073X.2008.00239.x)

Horiguchi K, Kikuchi M, Kusumoto K, Fujiwara K, Kouki T, Kawanishi K \& Yashiro T 2010 Living-cell imaging of transgenic rat anterior pituitary cells in primary culture reveals novel characteristics of folliculo-stellate cells. Journal of Endocrinology 204 115-123. (doi:10.1677/JOE-09-0333)

Horiguchi K, Kouki T, Fujiwara K, Kikuchi M \& Yashiro T 2011a The extracellular matrix component laminin promotes gap junction formation in the rat anterior pituitary gland. Journal of Endocrinology 208 225-232. (doi:10.1677/JOE-10-0297)

Horiguchi K, Fujiwara K, Ilmiawati C, Kikuchi M, Tsukada T, Kouki T \& Yashiro T $2011 b$ Caveolin 3-mediated integrin $\beta 1$ signaling is required for the proliferation of folliculostellate cells in rat anterior pituitary gland under the influence of extracellular matrix. Journal of Endocrinology 210 29-36. (doi:10.1530/JOE-11-0103)

Hynes RO 2002 Integrins: bidirectional, allosteric signaling machines. Cell 110 673-687. (doi:10.1016/S0092-8674(02)00971-6)

Inoue K, Couch EF, Takano K \& Ogawa S 1999 The structure and function of folliculo-stellate cells in the anterior pituitary gland. Archives of Histology and Cytology 62 205-218. (doi:10.1679/aohc.62.205)

Itakura E, Odaira K, Yokoyama K, Osuna M, Hara T \& Inoue K 2007 Generation of transgenic rats expressing green fluorescent protein in S-100beta-producing pituitary folliculo-stellate cells and brain astrocytes. Endocrinology 148 1518-1523. (doi:10.1210/en.2006-1390)
Kaidzu S, Noda T, Tane N \& Yashiro T 2000 Collagen synthesis by rat anterior pituitary cells in vivo and in vitro. Acta Histochemica et Cytochemica 33 81-87. (doi:10.1267/ahc.33.81)

Lazarides E \& Burridge K 1975 Alpha-actinin: immunofluorescent localization of a muscle structural protein in nonmuscle cells. Cell 6 289-298. (doi:10.1016/0092-8674(75)90180-4)

Li L \& Chaikof EL 2002 Mechanical stress regulates syndecan-4 expression and redistribution in vascular smooth muscle cells. Arteriosclerosis, Thrombosis, and Vascular Biology 22 61-68. (doi:10.1161/hq0102.100314)

Morand I, Fonlupt P, Guerrier A, Trouillas J, Calle A, Remy C, Rousset B \& Munari-Silem Y 1996 Cell-to-cell communication in the anterior pituitary: evidence for gap junction-mediated exchanges between endocrine cells and folliculostellate cells. Endocrinology 137 3356-3367. (doi:10.1210/en.137.8.3356)

Otey CA \& Carpen O 2004 Alpha-actinin revisited: a fresh look at an old player. Cell Motility and the Cytoskeleton 58 104-111. (doi:10.1002/cm. 20007)

Paez-Pereda M, Kuchenbauer F, Arzt E \& Stalla GK 2005 Regulation of pituitary hormones and cell proliferation by components of the extracellular matrix. Brazilian Journal of Medical and Biological Research 38 1487-1494. (doi:10.1590/S0100-879X2005001000005)

Parsons JT, Martin KH, Slack JK, Taylor JM \& Weed SA 2000 Focal adhesion kinase: a regulator of focal adhesion dynamics and cell movement. Oncogene 19 5606-5613. (doi:10.1038/sj.onc.1203877)

Pellegrin S \& Mellor H 2007 Actin stress fibres. Journal of Cell Science 120 3491-3499. (doi:10.1242/jcs.018473)

Sato Y, Hashitani H, Shirasawa N, Sakuma E, Naito A, Suzuki H, Asai Y, Sato G, Wada I, Herbert DC et al. 2005 Intercellular communications within the rat anterior pituitary XII: immunohistochemical and physiological evidences for the gap junctional coupling of the folliculostellate cells in the rat anterior pituitary. Tissue \& Cell 37 281-291. (doi:10.1016/j.tice.2005.03.005)

Sawaguchi N, Majima T, Iwasaki N, Funakoshi T, Shimode K, Onodera T \& Minami A 2006 Extracellular matrix modulates expression of cell-surface proteoglycan genes in fibroblasts. Connective Tissue Research 47 141-148. (doi:10.1080/03008200600685459)

Shirasawa N, Mabuchi Y, Sakuma E, Horiuchi O, Yashiro T, Kikuchi M, Hashimoto Y, Tsuruo Y, Herbert DC \& Soji T 2004 Intercellular communication within the rat anterior pituitary gland: $\mathrm{X}$. Immunohistocytochemistry of S-100 and connexin 43 of folliculo-stellate cells in the rat anterior pituitary gland. Anatomical Record. Part A, Discoveries in Molecular, Cellular, and Evolutionary Biology 278 462-473. (doi:10.1002/ar.a.20040)

Simons M \& Horowitz A 2001 Syndecan-4-mediated signalling. Cellular Signalling 13 855-862. (doi:10.1016/S0898-6568(01)00190-5)

Small JV, Rottner K, Kaverina I \& Anderson KI 1998 Assembling an actin cytoskeleton for cell attachment and movement. Biochimica et Biophysica Acta 1404 271-281. (doi:10.1016/S0167-4889(98)00080-9)

Soji T \& Herbert DC 1989 Intercellular communication between rat anterior pituitary cells. Anatomical Record 224 523-533. (doi:10.1002/ar. 1092240410)

Wiesner S, Legate KR \& Fässler R 2005 Integrin-actin interactions. Cellular and Molecular Life Sciences 62 1081-1099. (doi:10.1007/s00018$005-4522-8)$

Xian X, Gopal S \& Couchman JR 2010 Syndecans as receptors and organizers of the extracellular matrix. Cell and Tissue Research 339 31-46. (doi:10.1007/s00441-009-0829-3)

Received in final form 24 May 2012

Accepted 29 May 2012

Made available online as an Accepted Preprint 29 May 2012 